\title{
Incidência de contaminação no processo de obtenção do leite e suscetibilidade a agentes antimicrobianos
}

\section{Incidence of contamination in the process of getting milk and susceptibility to antimicrobial}

\author{
Patricia Regina Rocha Miguel ${ }^{1 *}$; Magali Soares dos Santos Pozza'; \\ Luiz Felipe Caron ${ }^{3}$; Maximiliane Alavarse Zambom²; Paulo Cesar Pozza ${ }^{2}$
}

\section{Resumo}

\begin{abstract}
A ordenha constitui-se em etapa fundamental para a obtenção de produtos lácteos com qualidade, sendo que, fatores relacionados à higiene dos tetos dos animais e dos equipamentos de ordenha podem levar à contaminação do leite elevando as contagens bacterianas deste produto. Tendo como objetivos avaliar a eficiência do pré-dipping na redução da contaminação bacteriana da pele dos tetos e do leite de vacas submetidas a diferentes condições de preparo para a ordenha e o perfil de suscetibilidade a antimicrobianos de bactérias presentes no leite, foram realizados experimentos em um rebanho leiteiro. Ao testar a eficiência do pré-dipping, observou-se diferença significativa no número de tetos com Staphylococcus $s p$ e bacilos Gram positivos entre os tratamentos sem higienização ou higienização com água e pré-dipping. Quanto à contagem bacteriana do leite, houve diferença significativa entre os tratamentos sem higienização e pré-dipping.. Quanto à suscetibilidade bacteriana a antimicrobianos, de oito testados, observou-se resistência a cinco, em pelo menos uma amostra, são eles: amoxicilina+ácido clavulânico, enrofloxacina, gentamicina, penicilina $\mathrm{G}$ e vancomicina. Os resultados permitiram concluir que: o pré-dipping representa importante ferramenta para reduzir a contaminação da pele dos tetos das vacas leiteiras, bem como do leite. A presença de Staphylococcus sp coagulase negativo resistente a certos antimicrobianos como a vancomicina não era esperada, sendo uma observação relevante do ponto de vista da qualidade do leite.
\end{abstract}

Palavras-chave: Leite, ordenha, pré-dipping, Staphylococcus

\begin{abstract}
The milking is a fundamental step for getting quality milk products, and factors related to the hygiene of the animal teats and of the milking equipment can take to contamination of the milk, raising this product's bacterian count. Experiments were carried to evaluate the efficiency of the predipping on teats bacterian contamination reduction and on bacterian count of milk from cows that have been submitted to different conditions of preparation for the milking, and the susceptibility to antimicrobials profile of milk bacteria. On the experiment that tested the efficiency of the predipping there was significant difference as to the number of teats with Staphylococcus sp and also positive Gram bacilli between treatments with no sanitation or with water sanitation and predipping. As to the milk bacterian count of the mammary quarters, there was significant difference between the treatments without sanitation and pre-dipping. As to the bacterian susceptibility to antimicrobials, it showed resistance to five, from the
\end{abstract}

1 Discente da Universidade Estadual do Oeste do Paraná, UNIOESTE, Marechal Cândido Rondon, PR. Parte da dissertação de mestrado. E-mail: patricia8m@hotmail.com

2 Profs. da UNIOESTE, Marechal Cândido Rondon, PR. E-mail: magaspozza@hotmail.com; mazambom@hotmail.com; pcpozza@yahoo.com.br

3 Prof. da Universidade Federal do Paraná, UFPR, Curitiba, PR. E-mail: caronvet@uol.com.br

* Autor para correspondência 
eight that were tested, in at least one sample, being them: amoxilicin+clavulanic acid, enrofloxacin, gentamicin, G penicillin and vancomycin. The results allowed to conclude that: the predipping represents and important tool to reduce contamination on teats, as well as on milk; the presence of coagulasenegative Staphylococcus sp resistant to certain antimicrobials, like vancomycin, wasn't expected, being a relevant observation from the milk quality point of view.

Key words: Milk, milking, predipping, Staphylococcus

\section{Introdução}

Segundo Corbia et al. (2000), dentre os alimentos de origem animal, o leite e seus derivados merecem destaque por serem produtos muito consumidos. Desta forma, do ponto de vista da saúde pública, a qualidade do leite é muito importante. Embora não existam, no Brasil, estatísticas que referenciem o assunto, são freqüentes casos de doenças associadas ao consumo de leite cru ou de derivados produzidos com leite contaminado com micro-organismos patogênicos (FAGUNDES; OLIVEIRA, 2004).

A maioria dos produtos lácteos é produzida a partir do leite pasteurizado e, por isso não deveriam representar riscos à saúde dos consumidores, porém, sabe-se que ocorre a comercialização de queijos artesanais elaborados a partir do leite cru, oferecendo perigo à saúde da população (GONÇALVES, 1998).

Segundo Vialta, Moreno e Valle (2002), o controle de qualidade no setor de laticínios iniciase bem antes da produção da matéria prima nas fazendas ou granjas leiteiras, pois o leite de boa qualidade só é obtido de animais, sadios, adequadamente manejados, bem nutridos e livres de doenças ou infecções. Na sequência, a ordenha deve ser realizada em condições higiênicas e ambiente apropriado. O leite precisa ser resfriado e transportado nestas condições até a indústria para que possa ser beneficiado.

Condições de resfriamento também interferem na qualidade microbiológica, porém, mesmo sob refrigeração, o leite pode servir como meio para a proliferação microbiana e ser deteriorado, já que algumas bactérias conseguem dobrar sua população a cada 20 ou 30 minutos (GUERREIRO et al., 2005). Isto reforça a necessidade do correto manuseio do leite desde a ordenha até o consumidor final, passando pela indústria.

Fagundes et al. (2006), ressaltam que, embora a refrigeração do leite logo após a ordenha seja uma medida obrigatória, isto não garante a qualidade do produto, reforçando que o mesmo seja obtido em condições higiênico-sanitárias adequadas para reduzir a possibilidade de contaminação inicial.. tTemperaturas de refrigeração em torno de $4^{\circ} \mathrm{C}$ selecionam uma microbiota psicrotrófico, produzindo enzimas termorresistentes que comprometem a qualidade dos derivados lácteos e principalmente do leite UHT (SANTANA et al., 2001).

A multiplicação de micro-organismos no leite tem o inconveniente de provocar alterações físico-químicas que limitam sua estabilidade. Em consequência disto, problemas econômicos e sanitários são gerados, tornando necessário o tratamento térmico visando a eliminação de microorganismos antes que o produto seja oferecido ao consumo humano (ALMEIDA, 1999).

A presença, de bactérias mesófilas em altas contagens em um alimento, é indicativo de procedimento higiênico inadequado na produção, no beneficiamento ou na conservação desse alimento. Considerando-se que todas as bactérias patogênicas de origem alimentar são mesófilas, a alta contagem representa que houve condições adequadas ao crescimento de patógenos (FRANCO; LANDGRAF, 1996).

Os patógenos associados à mastite, como Staphylococcus aureus e Streptococcus agalactiae, são transmitidos principalmente pelas mãos dos ordenhadores e equipamentos de ordenha, sendo que o número de infecções intramamárias pode ser reduzido significativamente através da desinfecção 
dos equipamentos de ordenha e antissepsia dos tetos dos animais e das mãos dos ordenhadores (PANKEY et al., 1987).

Diversos autores têm estudado as formas de preparação do úbere antes da ordenha, demonstrando os efeitos benéficos de práticas sanitizantes na redução da contaminação dos tetos e do leite (GALTON et al., 1982; GALTON, PETERSON; MERRILL, 1986; GALTON, PETERSON; MERRILL, 1988; GLESSON et al., 2009; HOGAN, WHITE; PANKEY, 1987; INGALLS, 2006; SCHULTZE, 1985).

Quanto aos equipamentos de ordenha, Glesson et al. (2009), destacaram as teteiras da ordenhadeira mecânica como a maior causa de contaminação entre as vacas, entretanto, o adequado manejo préordenha pode reduzir a contaminação dos tetos não só por bactérias ambientais como também por bactérias provenientes de outros animais.

Outro fator relacionado à segurança alimentar atualmente relevante, diz respeito à resistência bacteriana a antimicrobianos. A ANVISA (2002) destaca que este representa um sério risco à saúde humana, tornando-se um tema de muita importância, discutido intensamente em instituições como a Organização Mundial da Saúde, Organização Internacional de Epizootias e Codex Alimentarius.

Houve um rápido aumento na emergência de patógenos resistentes a múltiplas drogas nos últimos 10 a 15 anos (ROESCH et al., 2006). Algumas bactérias são resistentes à maioria dos agentes antimicrobianos, o que representa um problema crescente na medicina humana e veterinária (LEVY, 1998).

Aimportância da aquisição de bactérias resistentes a partir de alimentos de origem animal está mais relacionada à capacidade que possuem estes microorganismos de causar manifestações patológicas, caso sejam capazes de superar as barreiras impostas pelo sistema de defesa do organismo hospedeiro (PALERMO NETO; ALMEIDA, 2006). Porém, Poeta, Antunes e Rodrigues (2005), destacam que distintos genes de resistência podem ser trocados pelos micro-organismos presentes no intestino dos animais, ser adquiridos por micro-organismos saprófitas do intestino humano e, posteriormente, transferidos a possíveis patógenos, que podem ser disseminados a outros indivíduos.

O presente estudo teve como objetivos avaliar a eficiência do pré-dipping na redução da contaminação bacteriana da pele dos tetos e do leite de vacas submetidas a diferentes condições de preparo para a ordenha, a eficiência de higienização das teteiras da ordenhadeira mecânica, além do perfil de suscetibilidade a antibióticos de bactérias presentes no leite do tanque de refrigeração.

\section{Material e Métodos}

Foram realizados três experimentos, durante os quais, avaliou-se a eficiência do pré-dipping na redução do número de tetos contaminados e da contagem bacteriana do leite, a eficiência de higienização das teteiras da ordenhadeira mecânica e o perfil de suscetibilidade a antimicrobianos, de Staphylococcus sp coagulase negativos isolados de amostras de leite do tanque de refrigeração.

A pesquisa foi desenvolvida durante o período de novembro de 2009 a junho de 2010, no setor de bovinocultura de leite de uma instituição pública estadual de pesquisa e assistência técnica à Agricultura Familiar, localizada no município de Pinhais/Paraná. O rebanho era constituído por animais das raças Jersey, Pardo Suiço e Holandês, mantidos em sistema de criação agroecológico.

As análises microbiológicas foram realizadas no Laboratório de Patologia Básica do Setor de Ciências Biológicas da Universidade Federal do Paraná e no Laboratório do Programa de Análise de Rebanhos Leiteiros do Paraná (PARLPR), pertencente à Associação Paranaense de Criadores de Bovinos da Raça Holandesa.

Os dados foram submetidos à análise estatística utilizando o Programa SISVAR 5.0 (FERREIRA, 2003). 
tetos contaminados e na contagem bacteriana total do leite

Foram escolhidos 12 animais, com idade entre 36 e 48 meses, produção média diária de 12 litros de leite e resultado ao CMT (California mastitis test) não reagente ou, no máximo, $1+$.eOs mesmos foram distribuídos aleatoriamente em 3 grupos.sendo queCcada grupo recebeu um tratamento quanto à higienização dos tetos antes da ordenha: nenhuma higienização, higienização com água corrente e secagem com papel toalha descartável e pré-dipping com iodo e secagem com papel toalha descartável.

Foram amostrados dois tetos por animal, anterior direito (AD) e posterior esquerdo (PE), utilizandose $s w a b s$ esterilizados, os quais foram friccionados nas extremidades dos tetos, com movimentos rotativos após 30 segundos da secagem dos mesmos (RENDOS; EBERHART; KESLER, 1975) ou logo após a entrada e acomodação na sala de ordenha, quando animais do primeiro grupo. Os swabs foram mantidos em meio de transporte Stuart, acondicionados em caixa isotérmica contendo gelo e, em seguida, conduzidos ao laboratório da Universidade Federal do Paraná para pesquisa microbiológica. Ao todo foram analisadas 144 amostras durante o período experimental.

Foi feita a semeadura diretamente dos swabs para placas de Agar sangue que foram incubadas a $37^{\circ} \mathrm{C}$ por 24 horas. Após este período, as colônias foram analisadas quanto às características morfológicas e foi realizada a coloração de Gram.

Foi realizada a prova de coagulase em tubo das colônias de Staphylococcus (HOLMBERG, 1973)..

Os dados foram analisados quanto a número de tetos positivos para Staphylococcus sp e número de tetos positivos para bacilos Gram positivos.

Amostras individualizadas de leite foram coletadas diretamente dos tetos dos animais em frascos esterilizados contendo conservante, após terem sido desprezados os três primeiros jatos. Ao todo foram analisadas 48 amostras durante o período experimental.
As amostras de leite foram conduzidas ao Laboratório de controle leiteiro da APCBRH, onde foi realizada a contagem bacteriana total, através do ensaio de citometria de fluxo, em aparelho BactoCount IBC.

$\mathrm{O}$ delineamento experimental utilizado foi inteiramente casualizado, com 6 repetições para a coleta de amostras da pele dos tetos e 5 para amostras de leite dos quartos mamários. As médias foram comparadas pelo Teste de Student-NewmanKeuls (SNK), ao nível de significância de 5\%. O modelo estatístico utilizado para avaliar os efeitos dos tratamentos sobre o número de tetos positivos para Staphylococcus sp e bacilos Gram positivos, além da contagem bacteriana total do leite foi o seguinte:

$$
Y_{i j}=m+T_{i}+E_{i j}
$$

Onde:

$\mathrm{Y}_{\mathrm{ij}}=\mathrm{n}^{\mathrm{o}}$ de tetos positivos e contagem bacteriana total do leite, referentes aos tratamentos.

$\mathrm{m}=$ média geral da característica .

$\mathrm{T}_{\mathrm{i}}=$ efeitos dos tratamentos, sendo $\mathrm{i}=$ sem higienização, higienização com água e pré-dipping.

$\mathrm{E}_{\mathrm{ij}}=$ erro aleatório associado a cada observação.

Eficiência de higienização das teteiras da ordenhadeira mecânica

Foram coletadas amostras das teteiras da ordenhadeira mecânica, sendo 6 amostras antes da ordenha (teteiras higienizadas), 6 amostras após utilização em um animal, 6 amostras após utilização em dois animais e 3 amostras após utilização em 3 animais, perfazendo um total de 84 amostras durante o período experimental.

Foram utilizados swabs esterilizados, passados na superfície interna das teteiras em 20 movimentos circulares para cima, a partir da boca da borracha insufladora e 20 movimentos circulares para baixo, em uma altura de $15 \mathrm{~cm}$ (OLIVEIRA; BRUGNERA; PICOLLI, 2007). Após a coleta, cada swab foi colocado em frasco esterilizado contendo 
$10 \mathrm{ml}$ de solução salina esterilizada, identificado com o número da teteira, acondicionado em caixa isotérmica com gelo e levado ao laboratório.

Em câmara de fluxo laminar, foram retiradas alíquotas de $0,1 \mathrm{ml}$ de cada tubo com micropipeta, após agitação por 30 segundos, vertido em placa contendo Plate Count Agar (Ágar Padrão para Contagem) em duplicatas, sendo o material espalhado na placa com alça de Drigalski. As placas foram, em seguida, incubadas a $37^{\circ} \mathrm{C}$ por 24 horas. Após este período, as colônias foram contadas, sendo os valores expressos em unidades formadoras de colônias (UFC) x 10.

Para verificar o nível de contaminação das superfícies, as médias de unidades formadoras de colônias foram divididas por $117,75 \mathrm{~cm}^{2}$ (OLIVEIRA; BRUGNERA; PICOLLI, 2007), já que esta corresponde à área aproximada por onde foram passados os swabs.

O delineamento experimental utilizado foi inteiramente casualizado, com 4 repetições, sendo as médias comparadas pelo Teste de StudentNewman-Keuls (SNK), ao nível de significância de $5 \%$. O modelo estatístico utilizado para avaliar os efeitos do número de animais ordenhados sobre a contagem bacteriana total da superfície das teteiras foi o seguinte:

$$
Y_{i j}=m+T_{i}+E_{i j}
$$

Onde:

$\mathrm{Y}_{\mathrm{ij}}=$ contagens bacterianas, referentes ao número de animais ordenhados.

$\mathrm{m}=$ média geral da característica .

$\mathrm{T}_{\mathrm{i}}=$ efeitos dos tratamentos, sendo $\mathrm{i}=$ antes da ordenha, após ordenha de um, de dois e de três animais.

$\mathrm{E}_{\mathrm{ij}}=$ erro aleatório associado a cada observação.

Foi feita análise de regressão dos dados, segundo modelo linear de primeiro grau, dado pela seguinte fórmula:

$$
\mathrm{Y}_{\mathrm{i}}=\mathrm{B}_{0}+\mathrm{B}_{1} \mathrm{Y}_{\mathrm{i}}+\mathrm{E}_{\mathrm{i}}
$$

Onde:

$\mathrm{Y}_{\mathrm{i}}=$ observações de contagem bacteriana antes da ordenha, após um, dois e três animais.

$\mathrm{B}_{0}=$ constante ou coeficiente de introdução da reta com o eixo das ordenadas.

$\mathrm{B}_{1}=$ coeficiente de regressão linear da variável y, em função de $\mathrm{i}=$ antes da ordenha, após um, dois e três animais.

$\mathrm{E}_{\mathrm{i}}=$ erro aleatório associado a cada observação.

Perfil de suscetibilidade a antimicrobianos de Staphylococcus sp coagulase negativo isolados de amostras de leite do tanque de refrigeração

Foram coletadas amostras de leite do tanque de refrigeração em frascos esterilizados com auxílio de um coletor de aço inoxidável. As amostras foram levadas ao laboratório da UFPR em caixa isotérmica contendo gelo. As coletas foram realizadas semanalmente durante um período de quatro semanas.

Foi realizada a semeadura do material em ágar sangue e levado à incubação a $37^{\circ} \mathrm{C}$ por 24 horas. Após este período, foram identificadas colônias de Staphylococcus sp através de coloração de Gram e prova de catalase.

Utilizou-se o Método de Kirby \& Bauer(BAUER et al., 1966) para avaliar o perfil de suscetibilidade in vitro da bactéria isolada aos seguintes agentes antimicrobianos: amoxicilina+ácido clavulânico (30 mcg), cefalexina (30 mcg), enrofloxacina (5 mcg), gentamicina (10 mcg), levofloxacina (5 mcg), penicilina $\mathrm{G}$ (10 UI), tetraciclina (30 $\mathrm{mcg}$ ) e vancomicina (30 mcg), em concentrações recomendadas pelo National Committee for Clinical Laboratory Standards (NCCLS).

Segundo este método, colônias isoladas de Staphylococcus sp de uma cultura de 18 a 24 horas a $37^{\circ} \mathrm{C}$ foram tocadas com alça bacteriológica e 
inoculadas em salina fisiológica a $0,9 \%$ até que se obteve turvação semelhante a escala 0,5 de Mac Farland. Então, diluiu-se a suspensão com turvação 0,5 na escala Mac Farland a 1/10 em salina fisiológica, obtendo-se uma concentração bacteriana final de aproximadamente $10^{7}$ micro$\operatorname{organismos} / \mathrm{ml}$. Foi então inoculada a suspensão em Agar Mueller-Hinton com auxílio de swab esterilizado embebido na suspensão. Após a secagem da suspensão no ágar, os discos de antimicrobianos foram distribuídos de forma equidistante na placa, sem ultrapassar o tempo de 15 minutos. As placas foram incubadas a $37^{\circ} \mathrm{C}$ por 24 a 48 horas. Após este período, realizou-se a leitura através da visualização e mensuração dos diâmetros dos halos formados e, para a interpretação, foi utilizada a tabela padrão para interpretação de halos de inibição, de acordo com o NCCLS.

\section{Resultados e Discussão}

Eficiência do pré-dipping na redução do número de tetos contaminados e na contagem bacteriana total do leite

Houve diferença significativa entre os tratamentos para o número de tetos contaminados com Staphylococcus sp, como pode ser observado na Tabela 1, quando compara-se a não higienização ou a higienização com água com o pré-dipping. Da mesma forma, como pode ser observado na Tabela 2 , houve diferença significativa para o número de tetos contaminados com bacilos Gram positivos entre os tratamentos nos quais não houve higienização ou foi utilizada apenas água e o tratamento no qual foi utilizado o pré-dipping.

Tabela 1. Contaminação dos tetos com Staphylococcus sp em função dos tipos de higienização adotados (número de tetos).

\begin{tabular}{cccc}
\hline \multirow{2}{*}{ Ordenhas } & \multicolumn{3}{c}{ Tratamentos } \\
\cline { 2 - 4 } & Sem Higienização & Higienização com água & Pré-dipping \\
\hline 1 & 2 & 3 & 0 \\
2 & 8 & 4 & 4 \\
3 & 5 & 4 & 0 \\
4 & 8 & 7 & 6 \\
5 & 4 & 4 & 1 \\
6 & 7 & 5 & 1 \\
\hline Média & $5,6^{\mathrm{a}}$ & $4,5^{\mathrm{a}}$ & $2,0^{\mathrm{b}}$ \\
\hline
\end{tabular}

Médias seguidas de mesma letra, não diferem entre si ao nível de $5 \%$ de probabilidade pelo Teste SNK.

Fonte: Elaboração dos autores.

Tabela 2. Contaminação dos tetos com bacilos Gram positivos em função dos tipos de higienização adotados (número de tetos).

\begin{tabular}{cccc}
\hline \multirow{2}{*}{ Ordenhas } & \multicolumn{3}{c}{ Tratamentos } \\
\cline { 2 - 4 } & Sem Higienização & Higienização com Água & Pré-dipping \\
\hline 1 & 8 & 5 & 2 \\
2 & 8 & 8 & 8 \\
3 & 8 & 8 & 4 \\
4 & 7 & 5 & 5 \\
5 & 8 & 7 & 2 \\
6 & 7 & 7 & 3 \\
Média & $7,7^{\mathrm{a}}$ & $6,7^{\mathrm{a}}$ & $4,0^{\mathrm{b}}$ \\
\hline
\end{tabular}

Médias seguidas de mesma letra, não diferem entre si ao nível de 5\% de probabilidade pelo Teste SNK.

Fonte: Elaboração dos autores. 
A higienização com água não alterou significativamente a contaminação dos tetos, tanto com relação a Staphylococcus, como bacilos Gram positivos.

A utilização apenas de água na higienização propiciou uma redução do número de tetos contaminados com Staphylococcus e bacilos Gram positivos, porém, a redução foi significativamente maior quando foi utilizado o pré-dipping, indicando a necessidade desta prática antes da ordenha.

Brito, Brito e Verneque (2000), comprovaram a eficiência do pré-dipping em comparação ao uso de água corrente, porém, utilizando como parâmetro a contagem bacteriana da pele dos tetos.
Também utilizando a contagem bacteriana da pele dos tetos como parâmetro, Amaral et al. (2004) testaram os efeitos do pré-dipping com hipoclorito de sódio, concluindo ser este uma ferramenta importante na prevenção de mastite e na melhoria da qualidade do leite.

Houve diferença significativa entre os tratamentos sem higienização e pré-dipping para contagem bacteriana do leite retirado dos quartos mamários, sendo que o tratamento no qual foi utilizada apenas água manteve-se semelhante estatisticamente aos demais (Tabela 3 ).

Tabela 3. Médias das contagens bacterianas expressas em unidades formadoras de colônias x 1000/ml de leite retirado dos quartos mamários em função dos tipos de higienização.

\begin{tabular}{cccc}
\hline \multirow{2}{*}{ Repetição } & \multicolumn{3}{c}{ Tratamentos } \\
\cline { 2 - 4 } & Sem higienização & Higienização com água & Pré-dipping \\
\hline 1 & 31,00 & 11,00 & 7,50 \\
2 & 7,00 & 14,00 & 4,50 \\
3 & 2,50 & 2,00 & 1,25 \\
4 & 35,75 & 2,50 & 1,00 \\
5 & 65,50 & 24,50 & 4,00 \\
\hline Médias & $28,35^{\mathrm{a}}$ & $10,80^{\mathrm{ab}}$ & $3,65^{\mathrm{b}}$ \\
\hline
\end{tabular}

Médias seguidas por pelo menos uma mesma letra não diferem estatisticamente ao nível de 5\% de probabilidade pelo Teste SNK.

Fonte: Elaboração dos autores.

As altas contagens de mesófilos aeróbios no leite cru estão associadas a uma provável contaminação da matéria prima durante a sua obtenção. Este fato pode ser indicativo de falhas nos procedimentos higiênico-sanitários durante a ordenha ou manejo pré-ordenha, como a limpeza e desinfecção insuficiente dos tetos (SILVA et al., 2010).

Tem sido descrito que a antissepsia dos tetos e secagem com papel toalha antes da ordenha reduzem a contagem bacteriana da pele dos tetos e do leite (GALTON et al., 1982; GALTON; PETERSON; MERRILL, 1986; INGAWA; ADKINSON; GOUGH, 1992), além de prevenir infecções intramamárias (GALTON; PETERSON; MERRIL, 1988; SCHULTZE, 1985).
Galton, Peterson e Merril (1988), objetivando determinar os efeitos do pré-dipping em comparação à não higienização dos tetos antes da ordenha sobre a incidência de novas infecções intramamárias, comprovou uma redução de $66,3 \%$ no número de novas infecções por Streptococcus uberis inoculada experimentalmente.

Santana et al. (2001), compararam potenciais pontos de contaminação do leite em propriedades classificadas quanto ao manejo sanitário, encontrando redução de $99,5 \%$ nas contagens de aeróbios mesófilos na única propriedade que utilizava pré-dipping. Nas propriedades que utilizavam apenas água na higienização dos tetos, a redução situou-se entre 77 e $78 \%$. 
Eficiência de higienização das teteiras da ordenhadeira mecânica

As médias das contagens bacterianas das teteiras encontram-se na Tabela 4. Houve diferença significativa entre as médias dos períodos antes da ordenha, após ordenha de duas e de três vacas, permanecendo o valor obtido no período após ordenha de uma vaca sem diferença significativa em relação ao período anterior à ordenha e após ordenha de duas vacas.

A média de contagem bacteriana antes da ordenha - teteiras higienizadas - foi de $12,81 \times 10^{1}$
UFC, considerando a área por onde foram passados os swabs como sendo de aproximadamente 117,75 $\mathrm{cm}^{2}$, tem-se um valor de $1,09 \mathrm{UFC} / \mathrm{cm}^{2}$. Segundo a American Public Health Association - APHA, valores superiores a $2,0 \mathrm{UFC} / \mathrm{cm}^{2}$ em superfícies que entram em contato com alimentos, indicam higiene inadequada (EVANCHO et al., 2001). O processo de higienização praticado foi, portanto, eficiente na redução dos níveis de contaminação, que passaram de 12,00 UFC/ $\mathrm{cm}^{2}$ após a ordenha de três vacas, para $1,09 \mathrm{UFC} / \mathrm{cm}^{2}$.

Tabela 4. Médias das contagens bacterianas da superfície das teteiras expressas em unidades formadoras de colônias x 10/ $\mathrm{cm}^{2}$ em função do número de animais ordenhados.

\begin{tabular}{ccccc}
\hline Repetição & \multicolumn{4}{c}{ Número de animais ordenhados } \\
& Antes da ordenha & $\begin{array}{c}\text { Após ordenha de uma } \\
\text { vaca }\end{array}$ & $\begin{array}{c}\text { Após ordenha de duas } \\
\text { vacas }\end{array}$ & $\begin{array}{c}\text { Após ordenha de três } \\
\text { vacas }\end{array}$ \\
\cline { 2 - 5 } 1 & 12,25 & 67,67 & 132,91 & 163,00 \\
2 & 4,50 & 17,83 & 117,08 & 193,67 \\
3 & 26,16 & 30,33 & 55,58 & 85,83 \\
4 & 8,10 & 20,00 & 37,91 & 124,00 \\
\hline Médias & $12,81^{\mathrm{a}}$ & $33,96^{\mathrm{ab}}$ & $85,87^{\mathrm{b}}$ & $141,62^{\mathrm{c}}$ \\
\hline
\end{tabular}

Médias seguidas de mesma letra, não diferem entre si ao nível de 5\% de probabilidade pelo Teste SNK.

Fonte: Elaboração dos autores.

A higienização adequada reduz a contagem bacteriana das superfícies dos equipamentos de ordenha. Corroboram com esta afirmação resultados encontrados por Cavalcanti (2005), que, ao avaliar a eficiência dos procedimentos de higienização dos equipamentos de ordenha, obteve como média de contagem bacteriana das teteiras higienizadas $\mathrm{o}$ valor de $1,8 \mathrm{UFC} / \mathrm{cm}^{2}$.

Em experimento que testou a eficiência de higienização de equipamentos de ordenha manual quanto a contagem bacteriana, Costa (2006) observou uma redução de $90 \%$ da contaminação sob efeito da higienização.

Oliveira, Brugnera e Picolli (2007), destacaram a importância da correta higienização das teteiras ao estudar cinco propriedades leiteiras em Minas
Gerais, encontrando altos valores de contagem bacteriana mesmo quando as mesmas eram consideradas higienizadas.

Houve efeito linear positivo do número de animais ordenhados sobre a contagem bacteriana das superfícies das teteiras. Os dados estão representados na Figura1.

Os dados mostram uma evolução importante no aumento do número de bactérias à medida que os animais são ordenhados.

Silva et al. (2010), em experimento que avaliou, entre outros, a contaminação das teteiras durante a ordenha, descreveram aumentos das contagens médias de mesófilos aeróbios e coliformes totais e termotolerantes do início ao fim da ordenha. 
Este fato é importante por indicar que, apesar da higienização após o término da ordenha ocorrer de forma adequada, reduzindo significativamente a contaminação das superfícies das teteiras para a próxima ordenha, o risco encontra-se durante a ordenha.

Isto pode ser um indicativo da necessidade de medida de manejo, como a desinfecção das teteiras, entre ordenhas. Porém, a respeito disso, Amaral et al. (2004), ao testarem os efeitos da desinfecção das teteiras entre animais durante a ordenha, não encontraram efeitos significativos desta medida sobre a redução de bactérias, obtendo, inclusive, aumento do número de micro-organismos isolados. Estes autores destacam que o ato de imersão das teteiras em solução desinfetante pode promover o desprendimento de materiais aderidos à superfície interna das mesmas.

O desprendimento de materiais da superfície interna das teteiras, mesmo sem a ação de desinfecção entre um animal e outro, pode ser uma razão para a crescente contagem bacteriana verificada no presente trabalho, como resultado da umidade proporcionada pelo leite e a ação mecânica de contato com a pele do teto.

Deve-se considerar, portanto, que a contagem bacteriana das teteiras durante a ordenha é resultado da interação das mesmas com a pele dos tetos dos animais (SANTANA, et al., 2001), além do próprio leite.

Perfil de suscetibilidade de Staphylococcus sp. isolados de amostras de leite do tanque de refrigeração

$\mathrm{Na}$ Tabela 5 podem ser observados os dados obtidos nas provas de suscetibilidade de Staphylococcus sp isolados de 9 amostras de leite do tanque de refrigeração.

Figura 1. Regressão dos valores de contagem bacteriana (y) em função do número de animais ordenhados (x).

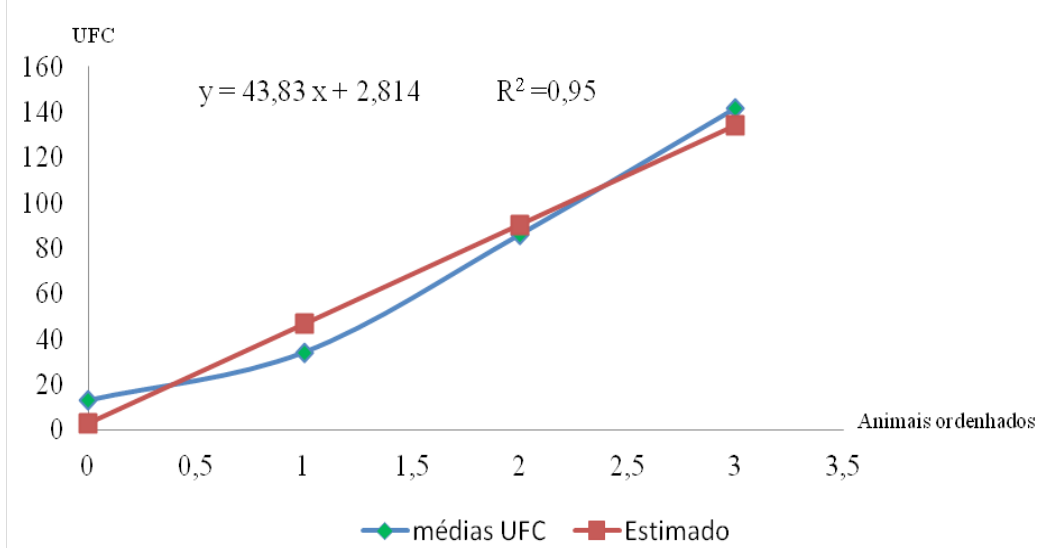

Fonte: Elaboração dos autores. 
Tabela 5. Perfil de suscetibilidade a antimicrobianos de Staphylococcus sp coagulase negativo isolados de amostras de leite do tanque de refrigeração.

\begin{tabular}{llllllllll}
\hline \multicolumn{1}{c}{ Antimicrobiano } & \multicolumn{9}{c}{ Amostras } \\
\cline { 2 - 10 } & $\mathrm{S}$ & 2 & 3 & 4 & 5 & 6 & 7 & 8 & 9 \\
\hline Amoxicilina/ Ác. Clavulânico & $\mathrm{S}$ & $\mathrm{S}$ & $\mathrm{S}$ & $\mathrm{S}$ & $\mathrm{S}$ & $\mathrm{S}$ & $\mathrm{S}$ & $\mathrm{S}$ & $\mathrm{R}$ \\
Cefalexinafalexina & $\mathrm{S}$ & $\mathrm{S}$ & $\mathrm{S}$ & $\mathrm{S}$ & $\mathrm{S}$ & $\mathrm{S}$ & $\mathrm{S}$ & $\mathrm{S}$ & $\mathrm{I}$ \\
Enrofloxacina & $\mathrm{R}$ & $\mathrm{S}$ & $\mathrm{S}$ & $\mathrm{S}$ & $\mathrm{S}$ & $\mathrm{S}$ & $\mathrm{S}$ & $\mathrm{S}$ & $\mathrm{S}$ \\
Gentamicina & $\mathrm{S}$ & $\mathrm{S}$ & $\mathrm{S}$ & $\mathrm{R}$ & $\mathrm{S}$ & $\mathrm{R}$ & $\mathrm{S}$ & $\mathrm{S}$ & $\mathrm{S}$ \\
Levofloxacina & $\mathrm{S}$ & $\mathrm{S}$ & $\mathrm{S}$ & $\mathrm{S}$ & $\mathrm{S}$ & $\mathrm{S}$ & $\mathrm{S}$ & $\mathrm{S}$ & $\mathrm{S}$ \\
Penicilina G & $\mathrm{S}$ & $\mathrm{S}$ & $\mathrm{S}$ & $\mathrm{S}$ & $\mathrm{S}$ & $\mathrm{S}$ & $\mathrm{S}$ & $\mathrm{S}$ & $\mathrm{R}$ \\
Tetraciclina & $\mathrm{S}$ & $\mathrm{S}$ & $\mathrm{S}$ & $\mathrm{S}$ & $\mathrm{S}$ & $\mathrm{S}$ & $\mathrm{S}$ & $\mathrm{S}$ & $\mathrm{S}$ \\
Vancomicina & $* \mathrm{~S}$ & $* \mathrm{~S}$ & $\mathrm{~S}$ & $\mathrm{~S}$ & $\mathrm{~S}$ & $\mathrm{~S}$ & $\mathrm{~S}$ & $\mathrm{~S}$ & $\mathrm{R}$ \\
\hline
\end{tabular}

$\mathrm{S}=$ sensível; $\mathrm{I}=$ sensibilidade intermediária; $\mathrm{R}=$ resistente.

*Houve crescimento de colônias satélite.

Fonte: Elaboração dos autores.

Dos oito antimicrobianos testados, observou-se resistência a cinco, em pelo menos uma amostra, são eles: amoxicilina+ácido clavulânico, enrofloxacina, gentamicina, penicilina $\mathrm{G}$ e vancomicina, sendo que a gentamicina apresentou a maior frequência, duas amostras.

Em três amostras, uma para penicilina $\mathrm{G}$ e duas para vancomicina, houve crescimento de colônias satélite, ou seja, em uma população sensível, havia indivíduos resistentes.

Ribeiro et al. (2009), em pesquisa de suscetibilidade bacteriana com linhagens de micro-organismos isolados do leite de vacas com e sem mastite, realizada com quatro rebanhos de produção orgânica de leite, relatou resistência a diversos antimicrobianos, entre eles, a gentamicina, enrofloxacina e penicilina.

Ao comparar os perfis de suscetibilidade de cepas de Staphylococcus sp e Streptococcus sp isolados do leite de propriedades com produção em sistemas orgânicos e convencionais, Roesch et al. (2006), não encontraram diferença siginificativa na resistência entre os dois sistemas de criação.

Pesquisadores têm relatado resistência de Staphylococcus spp isolados de leite a antimicrobianos como a gentamicina, enrofloxacina e penicilina (ZAFALON et al., 2008; MEDEIROS et al., 2009; RIBEIRO et al., 2009).
Alto percentual de espécimes de Staphylococcus $s p$. resistentes à penicilina foram descritos por Brito et al. (2001) e por Fontana (2002) em amostras de leite de vacas com mastite. Embora este antimicrobiano tenha sido muito utilizado no tratamento de infecções estafilocócicas em animais, na atualidade seu uso é restritodevido ao alto grau de resistência que tem sido observado. (LOWY, 1998).

Dentre os antimicrobianos estudados, destaca-se a vancomicina, que possui uso restrito em medicina veterinária e grande importância em medicina humana, tendo sido observada resistência em uma amostra e sensibilidade com crescimento de colônias satélite em duas amostras.

A vancomicina pertence à classe dos glicopeptídeos tricíclicos e tem como indicações, entre outras, as infecções graves por Staphylococcus e as septicemias bacterianas. Os glicopeptídeos, principalmente a vancomicina, tornaram-se uma das poucas alternativas terapêuticas eficazes no tratamento de infecções causadas por cepas de Staphylococcus aureus resistentes à oxacilina (ORSA), porém, tem sido descrita a emergência de cepas desta bactéria resistentes à vancomicina (FREITAS et al., 1991; OLIVEIRA et al., 2000).

Oliveira et al. (2001), ao estudarem a resistência à vancomicina de 395 cepas ORSA de Staphylococcus 
aureus isoladas de pacientes hospitalizados, encontraram frequência elevada de resistência, indicando a necessidade de maior vigilância quanto aos níveis de sensibilidade à vancomicina.

$\mathrm{Na}$ atualidade, o uso deste antibiótico vem sendo questionado devido ao elevado percentual de falhas terapêuticas constatadas na prática clínica da Medicina humana (DERESINSKI, 2007 apud LOPES, 2007).

Resistência à vancomicina em Enterococcus isolados de fezes de suínos e aves foi comprovada por Aarestrup et al. (1996). Este fato foi associado ao uso da avoparcina como aditivo em rações, comprovando resistência cruzada entre os dois antimicrobianos. A partir de 1997, a avoparcina passou a ser proibida como aditivo em rações na União Européia (POETA; ANTUNES; RODRIGUES, 2005).

Os Enterococcus resistentes à vancomicina apresentam grande importância na área médica, pois podem provocar surtos de infecção hospitalar de difícil controle, causando infecções graves e de limitadas opções terapêuticas (PALERMO NETO; ALMEIDA, 2006).

O conhecimento dos padrões de resistência antimicrobiana que apresentam os micro-organismos é de fundamental importância no desenvolvimento de métodos preventivos que sejam efetivos, assim como para a elaboração de estratégias de tratamento quando as mesmas se fizerem necessárias (SABOUR et al., 2004 apud ZAFALON et al., 2008).

Os resultados permitem concluir que:

O pré-dipping é uma importante ferramenta para reduzir a contaminação da pele dos tetos, ficando evidente o potencial risco à contaminação do leite quando não praticado.

A resistência a antimicrobianos observada entre isolados de Staphylococcus sp foi relevante, não estando de acordo com o esperado, principalmente quando relacionada à vancomicina, podendo representar um ponto crítico à obtenção de leite com qualidade.

\section{Referências}

AARESTRUP, F. M.; AHRENS, P.; MADSEN, M.; PALLESEN, L. V.; POULSEN, R. L.; WESTH, H. Glycopeptide susceptibility among danish enterococcus faecium and enterococcus faecalis isolates of animal and human origin and pcr identification of genes within the vana cluster. Antimicrobial Agents and Chemotherapy, Washington, v. 40, n. 8, p. 1938-1940, 1996.

AMARAL, L. A.; HINIG, I.; DIAS, L. T.; ROSSI JUNIOR, O. D.; NADER FILHO, A. Avaliação da eficiência da desinfecção de teteiras e dos tetos no processo de ordenha mecânica de vacas. Pesq. Vet. Bras., Rio de Janeiro, v. 24, n. 4, p. 173-177, 2004.

BAUER, M. D.; KIRBY, W. M. M.; SHERRIS, J. C.; TURK, M. Antibiotic susceptibility testing by a standardized single disk method. Am. J. Clin. Pathol., Chicago, v. 45, n. 4, p. 493-496, 1966.

BRASIL. Ministério da Saúde. Agência Nacional de Vigilância Sanitária. ANVISA. XIX Congresso Nacional de Laticínios. Mesa Redonda: Segurança alimentar na cadeia do leite. controle de alimentos - aplicação dos princípios de análise de riscos. 17 de julho de 2002.

BRITO, J. R. F.; BRITO, M. A. V. P. e; VERNEQUE, R. da S. Contagem bacteriana da superfície de tetos de vacas submetidas a diferentes processos de higienização, incluindo a ordenha manual com participação do bezerro para estimular a descida do leite. Ciência Rural, Santa Maria, v. 30, n. 5, p. 847-850, 2000.

BRITO, M. A. V. P.; BRITO, J. R. F.; SILVA, M. A. S.; CARMO, R. A. Concentracão mínima inibitória de dez antimicrobianos para amostras de Staphylococcus aureus isoladas de infecção intramamária bovina. Arquivo Brasileiro de Medicina Veterinária e Zootecnia, Juiz de Fora, v. 53, n. 5, p. 531-537, 2001.

CAVALCANTI, E. R. C. Construção do conhecimento sobre o potencial de contaminação em ordenhadeiras mecânicas após higienização. 2005. Dissertação (Mestrado em Educação Agrícola) - Universidade Federal Rural do Rio de Janeiro, Rio de Janeiro.

CORBIA, A. C. G.; NASCIMENTO, M. da G. F.; OLIVEIRA, C. Z. F.; NASCIMENTO, E. R. Staphylococcus aureus: importância para a saúde pública e aspectos epidemiológicos. Seropédica: Embrapa Agrobiologia, dez. 2000. 15 p. (Embrapa-CNPAB. Documentos, 114).

COSTA, F. F. da. Interferência de práticas de manejo na qualidade microbiológica do leite produzido em propriedades rurais familiares. 2006. Dissertação (Mestrado em Zootencia) - Universidade Estadual Paulista Júlio de Mesquita Filho, Jaboticabal. 
EVANCHO, G. M.; SVEUM, W. H.; MOBERG, L. J.; FRANK, J. F. Microbiological monitoring of the food processing environment. In: DOWNES, F. P.; ITO, K. Compendium of methods for the examination of foods. 4 . ed. Washington: APHA, 2001.

FAGUNDES, C. M.; FISCHER, V.; SILVA, W. P. da; CARBONERA, N.; ARAÚJO, M. R. Presença de Pseudomonas spp em função de diferentes etapas da ordenha com distintos manejos higiênicos e no leite refrigerado. Ciência Rural, Santa Maria, v. 36, n. 2, p. 568-572 2006.

FERREIRA, D. F. SISVAR 5.0. Lavras, MG: Universidade Federal de Lavras, 2003.

FONTANA, V. L. D. S. Etiologia da mastite bovina subclínica da região de Jataí/GO. Padrão genético e de suscetibilidade a drogas antimicrobianas com ênfase ao gênero Staphylococcus. Araraquara: Universidade Estadual Paulista Julia de Mesquita Filho, 2002. 61 p.

FRANCO, B. G. M. F.; LANDGRAF, M. Microbiologia dos alimentos. São Paulo: Atheneu, 1996. 182 p.

FREITAS, C. C.; ESPÓSITO, R. C.; COSTA, M. A. B.; CABALLIDO, J. Tolerância a antibióticos em cepas de Staphylococcus aureus isoladas de pacientes do HUAPUFF. Arq. Bras. Med., Rio de Janeiro, v. 65, n. 5, p. 116S, 1991.

GALTON, D. M.; ADKINSON, R. W.; THOMAS, C. V.; SMITH, T. W. Effects of premilking udder preparation on environmental bacterial contamination of milk. Journal of Dairy Science, Savoy, v. 65, n. 8, p. 1540-1543, 1982.

GALTON, D. M.; PETERSON, L. G.; MERRILL, W. G. Effects of premilking udder preparation practices on bacterial counts in milk and on teats. Journal of Dairy Science, Savoy, v. 69, n. 1, p. 260-266, 1986.

GALTON, D. M.; PETERSON, L. G.; MERRIL, W. G. Production technical notes: evaluation of udder preparations on intramammary infections. Journal of Dairy Science, Savoy, v. 71, n. 5, p. 1417-1421, 1988.

GLESSON, D.; O'BRIEN, B.; FLYN, J.; O'CALLAGHAN, E.; GALLI, F. Effect of pre-milking teat preparation procedures on the microbial count on teats prior to cluster application. Irish Veterinary Journal, Dublin, v. 62, n. 7, p. 461-467, 2009.

GUERREIRO, P. K.; MACHADO, M. R. F.; BRAGA, G. C.; GASPARINO, E.; FRANZENER, A. S. M. Qualidade microbilógica de leite em função de técnicas profiláticas no manejo de produção. Ciências Agrotécnicas, Lavras, v. 29 , n. 1 , p. $216-222,2005$.

HOGAN, J. S.; WHITE, D.G.; PANKEY, J. W. Effects of teat dipping on intramammary infections by staphylococci other than staphylococcus aureus. Journal of Dairy Science, Savoy v. 70, n. 1, p. 216-222, 1987.

HOLMBERG, O. Staphylococcus epidermidis isolated from bovine milk. Acta Vet Scand, London, v. 45, p. 1-144, 1973. Suplemento.

INGALLS, W. Industry presentation. Procedures and products required for milking center efficiency, mastitis control and production of high quality milk. High Plains Dairy Conference. Industry Presentation. Kansas City: DeLaval Inc., 2006.

INGAWA, K. H.; ADKINSON, R. W.; GOUGH, R. H. Evaluation of a gel teat cleaning and sanitizing compound for premilking hygiene. Journal of Dairy Science, Savoy, v. 75, n. 5, p. 1224-1232, 1992.

LEVY, S. B. The challenge of antibiotic resistance. Scientific American, march, 1998. Disponível em: $<$ http://www.bio.utexas.edu/courses/kalthoff/bio301C/ readings/06Levy.pdf.> Acesso em: 25 ago. 2009.

LOPES, H. V. O Papel atual da vancomicina nas infecções estafilocócicas. Rev. Panam. Infectol., São Paulo, v. 9, n. 3, p. 70-71, 2007.

LOWY, F. D. Staphyococcus aureus infections. New England Journal Medicine, New York, v. 339, n. 8, p. 520-532, 1998.

MEDEIROS, E. S.; MOTA, R. A.; SANTOS, M. V.; FREITAS, M. F. L.; PINHEIRO JUNIOR, F. W.; TELES, J. A. A. Perfil de sensibilida de microbiana in vitro de linhagens de Staphylococcus spp. isoladas de vacas com mastite subclínica. Pesq. Vet. Bras., Rio de Janeiro, v. 29, n. 7, p. 569-574, 2009.

OLIVEIRA, G. A.; OKADA, S. S.; GUENTA, R. S.; MAMIZUKA, E. M. Avaliação da tolerância à vancomicina em 395 cepas hospitalares de Staphylococcus aureus resistentes à oxacilina. J. Bras. Patol. Med. Lab., Rio de Janeiro, v. 37, n. 4, p. 239-246, 2001.

OLIVEIRA, G. A.; LEVY, C. E.; MAMIZUKA, E. M. Estudo do perfil de resistência de 626 cepas de Staphylococcus aureus isoladas de 25 hospitais brasileiros entre setembro de 1995 e junho de 1997. J. Bras. Pat. Med. Lab., Rio de Janeiro, v. 36, n. 2, p. 147-56, 2000.

PALERMO NETO, J. P.; ALMEIDA, R. T. Antimicrobianos como Aditivos em Animais de Produção. In: SPINOSA, H. S.; GÓRNIAK, S. L.; BERNARDI, M. M. Farmacologia aplicada à medicina veterinária. 4. ed. Rio de Janeiro: Guanabara Koogan, 2006.

PANKEY, J. W.; WILDMAN, E. E.; DRECHSLER, P. A.; HOGAN, J. S. Field trial evaluation of premilking teat disinfection. Journal Dairy Science, Savoy, v. 70, n. 4, p. 867-872, 1987. 
POETA, P.; ANTUNES, T.; RODRIGUES, J. Enterococcus spp isolados de fezes de frangos, pombos, gamos e ratos. Arq. Bras. Med. Vet. Zootec., Belo Horizonte, v. 58, n. 3, p. 412-414, 2005.

RENDOS, J. J.; EBERHART, R.J.; KESLER, E. M. Microbial populations of teat ends of dairy cows, and bedding materials. Journal Dairy Science, Savoy, v. 58, n. 10, p. $1492-1500,1975$.

RIBEIRO, M. G.; GERALDO, J. S.; LANGONI, H.; LARA, G. H. B.; SIQUEIRA, A. K.; SALERNO, T.; FERNANDES, M. C. Micro-organismos patogênicos, celularidade e resíduos de antimicrobianos no leite bovino produzido no sistema orgânico. Pesq. Vet. Bras., Rio de Janeiro, v. 29, n. 1, p. 52-58, 2009.

ROESCH, M.; PERRETEN, V.; DOHERR, M. G.; SCHAEREN, W.; SCHÄLLIBAUM, M.; BLUM, J. W. Comparison of antibiotic resistance of udder pathogens in dairy cows kept on organic and on conventional farms. Journal Dairy Science, Savoy, v. 89, n. 3, p. 989-997, 2006.
SANTANA, E. H. W. de; BELOTI, V.; BARROS, M. A. F.; MORAES, L. B.; GUSMÃO, V. V.; PEREIRA, M. S. Contaminação do leite em diferentes pontos do processo de produção: I. Microrganismos aeróbios mesófilos e psicrotróficos. Semina: Ciências Agrárias, Londrina, v. 22, n. 2, p. 145-154, 2001.

SCHULTZE, W. D. Control of new intramammary infection at calving by prepartum teat dipping. Journal Dairy Science, Savoy, v. 68, n. 8, p. 2094-2099, 1985.

SILVA, V. A. de M. da; RIVAS, P. M.; ZANELA, M. B.; PINTO, A. T.; RIBEIRO, M. E. R.; SILVA, F. F. P.; MACHADO, M. Avaliação da qualidade físico-química e microbiológica do leite cru, do leite pasteurizado tipo a e de pontos de contaminação de uma granja leiteira no RS. Acta Scientiae Veterinariae, Porto Alegre, v. 38, n. 1, p. 51-57, 2010.

ZAFALON, L. F.; ARCARO, J. R. P.; NADER FILHO, A.; FERREIRA, L. M.; CASTELANI, L.; BENVENUTTO, F. Investigação de perfis de resistência aos antimicrobianos em Staphylococcus aureus isolados na ordenha de vacas em lactação. Rev. Inst. Adolfo Lutz, São Paulo, v. 67, n. 2, p. 118-125, 2008. 
